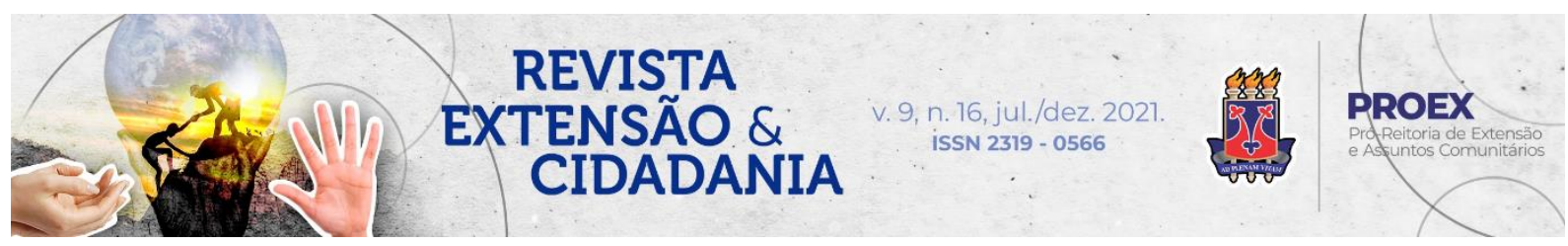

DOI: $10.22481 /$ recuesb.v9i16.9632

\title{
PAPO LÍRICO ENTRE CELAS: OFICINAS DE LITERATURA E CINEMA NO CONJUNTO PENAL DE JEQUIÉ
}

\section{PAPO LIIRICO BETWEEN CELLS: CINEMA AND LITERATURE WORKSHOPS IN THE JEQUIÉ PENAL COMPLEX SCHOOL}

\section{PAPO LÍRICO ENTRE CELDAS: TALLERES DE LITERATURA Y CINE EN EL COMPLEJO PENAL JEQUIÉ}

\author{
Valeria Lessa Mota $^{1}$ \\ Anísio Assis Filho ${ }^{2}$ \\ Ana Letícia de Jesus Silva ${ }^{3}$ \\ Elenita Brito Aragão Assis ${ }^{4}$ \\ Emanoel Jorge Leal Braga ${ }^{5}$ \\ Domingos Calixto dos Santos 6
}

Resumo: Em 2018, o Papo Lírico, Programa de Extensão da UESB, realizou as Oficinas de Literatura e Cinema que objetivavam ler e discutir obras cinematográficas e literárias prioritariamente baianas, no Complexo Penal de Jequié, com grupos formados por pessoas em tempos formativos diversos e com repertórios culturais diferenciados. Este relato objetiva apresentar esta experiência vista a partir de 2021, no cenário ainda de pandemia da Covid-19. As ações foram organizadas na concepção de oficina e de roda de conversa proposta por estudiosos inspirados pela educação emancipadora de Paulo Freire (1996), quem, ao lado de Antonio Augusto G. Batista (1991), orienta a visão sobre a leitura. A noção de arte

\footnotetext{
${ }^{1}$ Licenciada em Letras. Mestre em Literatura e Diversidade Cultural. Professora da área de Literatura Brasileira e Teoria da Literatura, da Universidade Estadual do Sudoeste da Bahia, campus de Jequié, Bahia, Brasil. Orcid: https://orcid.org/0000-0002-6288-3748 E-mail: valeria.lessa@uesb.edu.br

${ }^{2}$ Licenciado em Letras. Mestre em Letras, Cultura, Educação e Linguagens. Professor da área de Literatura Brasileira e Teoria da Literatura da Universidade Estadual do Sudoeste da Bahia, campus de Jequié, Bahia, Brasil. Orcid: https://orcid.org/0000-0002-3671-3278 E-mail: anisioassisfilho@gmail.com

${ }^{3}$ Graduada em Letras, pela Universidade Estadual do Sudoeste da Bahia, campus de Jequié, Bahia, Brasil. Orcid: Orcid: https://orcid.org/0000-0001-9551-874X E-mail: analeticia02@outlook.com

${ }^{4}$ Graduada em Letras; Especialista em Língua Portuguesa e Literatura Brasileira. Professora da rede pública de ensino da Bahia, Jequié, Bahia, Brasil. Orcid: https://orcid.org/0000-0003-3421-3541 E-mail: elenita.aragao@enova.educacao.ba.gov.br

${ }^{5}$ Graduado em Letras; Especialização em Antropologia com ênfase na Cultura Afro-brasileira, Jequié, Bahia, Brasil. Orcid: https://orcid.org/0000-0002-2502-2631 E:mail: emanoelbraga@gmail.com

${ }^{6}$ Graduado em Letras; Especialista em Língua Portuguesa e Literatura. Professor da rede estadual de ensino da Bahia, Jequié, Bahia, Brasil. Orcid: https://orcid.org/0000-0003-3421-3541 E-mail: domingos.calixto@enova.educacao.ba.gov.br
} 
fundamentou-se em Alfredo Bosi (2004), a de ficção estriba-se na perspectiva de Antonio Candido (1989) e Wolfgang Iser (2002). Tais suportes teóricos amparam a discussão das ações, que propiciaram debates e reflexões acerca das relações entre leitor, vida e mundo, rememorações, construções de outras histórias em um movimento humanizador. Esse resultado foi tão positivo que as oficinas foram replicadas com grupos e em ambientes variados, como a praça pública e evento acadêmico. As oficinas e rodas de conversa sobre modalidades artísticas podem ser cada vez mais alternativas oportunas de atividades coletivas em múltiplos espaços de discussão e mais uma via de oposição à crescente onda segregacionista no país.

Palavras-chave: Leitura. Literatura baiana. Cinema. Educação. Espaços socioeducativos e prisionais.

Abstract: In 2018, Papo Lírico, UESB's Extension Program, held Literature and Cinema Workshops that aimed to read and discuss primarily Bahian cinematographic and literary works at the Jequié Penal Complex, with groups formed by people with different educational backgrounds and also with different cultural repertoires. Through the workshops, developed as conversation circles, the reading of short fictional works favored debates on the relationships between the reader, life and the world, considering that both reading and its object are productions of meaning that rely on the reader's worldview, on his repertoire and class culture and enables him an experience on rewriting that involves self-understanding and reflection on reality. Afterwards, the workshops were held with different groups and in other environments, including the academic. After initial estrangement, the participants got involved in the proposed discussions on the relationship between reader and text, relationship with life and elaboration of self and the other. Understandably, the academic group, made up of undergraduates in Arts, explored the materialities more than others. The Covid-19 pandemic exacerbated individualism, distance, and inequality, in addition to accentuating illness. The feelings provoked by isolation call for urgent changes such as the construction and solidification of ways of living that overcome barriers to equality and brotherhood. Workshops and conversation circles on artistic modalities are increasingly becoming opportune alternatives for collective activities in multiple spaces for discussion and yet another way of opposing the growing segregationist wave in the country.

Keywords: Bahian literature. Reading. Cinema. Education. Socio-educational space and prison.

Resumen: En 2018, Papo Lírico, Programa de Extensión de la UESB, realizó Talleres de Literatura y Cine que tuvieron como objetivo la lectura y discusión de obras cinematográficas y literarias principalmente bahianas en lo Complejo Penal Jequié con grupos formados por personas de diferentes épocas educativas y con diferentes repertorios culturales. Este informe tiene como objetivo presentar esta experiencia, vista a partir de 2021, en el escenario aún pandémico de Covid-19. Los talleres se organizaron a partir del concepto de taller y círculo de conversación propuesto por académicos inspirados en la educación emancipadora de Paulo Freire (1996), quien, junto a Antonio Augusto G. Batista (1991), orienta la mirada sobre la lectura. La noción de arte se basó en Alfredo Bosi (2004), la de ficción se basó en la perspectiva de Antonio Candido (1989) y Wolfgang Iser (2002). Dichos soportes teóricos sustentan la discusión de los talleres, que brindaron debates y reflexiones sobre las relaciones entre lector, vida y mundo, recuerdos, construcciones de otras historias en un movimiento humanizador. Este resultado fue tan positivo que los talleres se replicaron con grupos y en diferentes ambientes, como la plaza pública y el evento académico. Los talleres y círculos de conversación

Revista Extensão \& Cidadania, v. 9, n. 16, p. 253-266, jul./dez. 2021.

ISSN 2319-0566 DOI: 10.22481/recuesb.v9i16.9632 
sobre modalidades artísticas se están convirtiendo cada vez más en alternativas oportunas para las actividades colectivas en múltiples espacios de discusión y una forma más de oponerse a la creciente ola segregacionista en el país.

Palabras clave: Literatura bahiana. Lectura. Cine. Educación. Espacios socioeducativos y prisioneros.

\section{Introdução}

A pandemia da Covid-19 acontece em um cenário de mundialização do capital a serviço do qual o Estado se organiza, desresponsabilizando-se cada vez mais celeremente da gestão de mediação entre as forças na sociedade de classes o que leva ao caminho da barbárie do lucro acima da sociedade, da humanização e do meio ambiente. Conforme Marques e outros (2021), a pandemia desmascarou a intensa e crescente desigualdade e reclama a necessidade de construir e solidificar modos de viver que unam ao invés de separar, que nos permitam a igualdade de condições e de direitos. O flagelo instigou lembranças e atualizou maneiras arcaicas de trabalho. À moda das guildas, mas em suportes midiáticos, os participantes do Projeto Papo Lírico 2021 se reuniram para registrar a experiência realizada na Escola Anexa ao Conjunto Penal de Jequié, em 2018, este texto é o resultado desse reencontro.

O Papo Lírico, ação extensionista da Área de Estudos Literários, do Departamento de Ciências Humanas e Letras (DCHL), da Universidade Estadual do Sudoeste da Bahia (UESB), tendo por base as pesquisas sobre escritores baianos, nasceu em 2002 como evento, cresceu como extensão continuada e, como Programa se estrutura em ações variadas que visam divulgar a literatura do Estado, incentivar a formação crítica e a criação artístico-literária em diálogo com a comunidade. A partir do convite de dois professores que atuam na Escola Anexa ao Conjunto Penal de Jequié, é que, em 2018, foi planejada a ação objeto deste relato. Institucionalizada a parceria, esta foi viabilizada porque, naquele ano, o Programa obteve financiamento da UESB, contando com uma monitora bolsista e, na fase preparatória, com dois monitores voluntários. Além destes, teve a colaboração de um membro da comunidade, experiente em ações comunitárias em espaços variados, inclusive o prisional (Funcionário da Prefeitura Municipal de Jequié) e do apoio do setor de audiovisual do campus de Jequié A proposta da ação foi ler e discutir obras artísticas, cinematográficas e literárias prioritariamente baianas, com os alunos da Escola Anexa ao Conjunto Penal de Jequié.

Revista Extensão \& Cidadania, v. 9, n. 16, p. 253-266, jul./dez. 2021. 
Criada em 1998, a Unidade Penal já foi ampliada e tem capacidade para 416 internos, mas como em outras unidades prisionais no país, a lotação não é respeitada e abriga hoje 556 pessoas entre o sexo masculino e feminino, condenados ao cumprimento de pena em regimes fechado e semiaberto, bem como de presos provisórios das Comarcas relacionadas ao Provimento da Corregedoria Geral de Justiça nº 03/2016 (BAHIA, 2016).

O Conjunto Penal de Jequié é composto por 8 módulos de vivência, em consonância à Lei de Execução Penal (BRASIL, 1984) e à Lei de Diretrizes e Bases da Educação (BRASIL, 1996), há a oferta de educação gratuita nos turnos matutino e vespertino, na modalidade de Educação de Jovens e Adultos (EJA) para ambos os sexos, em 5 módulos sendo: 4 módulos para o sexo masculino e 1 módulo para o feminino.

Atualmente, a EJA é ofertada pelo Colégio Estadual Luiz Navarro de Brito, que tem sua sede no bairro KM 3, na cidade de Jequié, e possui no Conjunto Penal de Jequié uma Escola Anexa, mantendo o mesmo nome da escola sede, com a mesma gestão geral e um vice-diretor local. Em 2018, entretanto, a Escola Anexa era ainda vinculada ao Colégio Estadual Professora Georgina Miranda, situada no bairro Jequiezinho.

\section{Metodologia}

A implementação do ensino em ambiente de privação de liberdade apresenta aspectos que são estritamente peculiares a este meio, os quais foram considerados na proposição da ação do Papo Lírico e na sua consecução. Destaque-se dentre eles, o modelo de correção ressocializadora que regulamenta o discurso jurídico sobre o assunto, conforme apontado por Clarissa Maia (2009) e Daniel Fernandes (2018), que se constrói e auxilia construir no imaginário social a figura do aluno que é "bandido". A perspectiva educadora que fundamenta o fazer pedagógico precisa lidar com essa dualidade e orientar-se para um aluno como ser humano que possui um histórico de múltiplas violências, inclusive no âmbito educacional e com direito a uma educação crítico-reflexiva, que contribua para o aluno entender-se cidadão, capaz de reconstruir elos de cidadania e ressignificação humana. Desconstruindo aquilo que Paulo Freire (1996) chama de introspecção de uma culpa indevida, esta relativa à estigmatização dos alunos privados de liberdade e seus possíveis sentimentos de marginalização, de serem e terem nascidos delinquentes.

Revista Extensão \& Cidadania, v. 9, n. 16, p. 253-266, jul./dez. 2021. 
A ação docente dá-se no intervalo entre os sons ressonantes das portas que se fecham à entrada e saída das salas e faz latejar as paredes de uma violência em potencial que não se esgota na privação de liberdade. Esse espaço pode ser definido com as palavras de Denise Carrascosa (2015, p. 13) sobre as cadeias brasileiras: “ferozes mecanismos materiais e simbólicos de subalternização, apagamentos subjetivos e violentação daquilo que é correntemente entendido como condição humana". Integrada ao módulo presidiário, a sala de aula é um espaço de detenção para os envolvidos no processo de ensino-aprendizagem, situa-se em um lugar incerto: dentro e fora do cárcere. Efeito similar à atividade dos professores e das professoras que também, momentaneamente, estão privados de sua liberdade e que devido a isto precisam controlar os próprios gestos e as práticas docentes. Para o interno, a classe onde ocorre a aula pode ser uma sala coletiva dentre outras do presídio, mas que pode lhe abrir, senão portas, frestas para possíveis liberdades.

A esse aspecto do ensino no ambiente prisional, destaca-se um outro que interfere na docência e no funcionamento da Escola Anexa ao Conjunto Penal de Jequié. Cada um dos 5 módulos tem a sua classe específica composta daqueles que querem e podem participar da formação educacional. Não é possível ao residente de um módulo frequentar a classe de outro módulo. Com isso, as classes são compostas por alunos de níveis escolares diferentes e quase sempre possuem duas turmas, de tempos formativos ou eixos diferentes que ocupam a mesma sala ao mesmo tempo. Não obstante, a característica majoritária da população carcerária do Brasil, as classes da Escola Anexa ao Conjunto Penal de Jequié têm um perfil de educandos comparável ao das escolas públicas brasileiras quanto ao repertório artístico-cultural, nível econômico e social. Aponte-se ainda a configuração incerta da classe a cada encontro em decorrência, dentre outras coisas, de alvarás e transferências de módulos ou unidade prisional.

O Papo Lírico entre Celas foi planejado tendo em vista o ambiente socioeducacional penal com seus estigmas, sua condição subalterna e submetida, os grupos variados tanto do ângulo da formação educacional quanto do repertório cultural e de classe social. Foram consideradas ainda as relações de poder que se constituem fora e dentro do sistema prisional, que se reproduzem não apenas nas leis, mas no discurso verdadeiro que decide, transmite e reproduz, ao menos em parte, efeitos de poder, operante nos corpos, gestos, discursos e desejos, conforme apontado por Michel Foucault (1979). O intuito era, e faz-se cada vez mais relevante quando grande parte da população é coisificada e vista como descartável, fruir a arte, ou seja,

Revista Extensão \& Cidadania, v. 9, n. 16, p. 253-266, jul./dez. 2021. 
cultivar o caráter criador, crítico, formativo e sensibilizador das obras produzidas por artistas regionais e, ao mesmo tempo, divulgar essas criações. O problema, portanto, era promover atividades em que as dessemelhanças, de valores, status, repertórios dos envolvidos na prática extensionista não fossem empecilhos para o diálogo e o intercâmbio de experiências da maneira mais igualitária possível.

A oficina foi escolhida por sua eficiência do ponto de vista estrutural e do ponto de vista pedagógico, como afirmam Léa Anastasiou e Leonir Alves (2004, p. 95), essa maneira de proceder é "lugar de pensar, descobrir, reinventar, criar e recriar, favorecido pela forma horizontal na qual a relação humana se dá”. Abre possibilidade para o uso de recursos variados desde músicas e textos a observações diretas, vídeos, experiências práticas, dando lugar à "vivenciar ideias, sentimentos, experiências, num movimento de reconstrução individual e coletiva" (ANASTASIOU; ALVES, 2004, p. 95), e como dizem Elaine Vieira e Lea Volquind (2002, p. 11), pode instalar "troca de relações, funções, papéis entre educadores e educandos" e articular e integrar saberes.

A oficina favorece uma práxis, a vivência artística e a reflexão sobre ela, realizadas por todos os envolvidos, por meio das "rodas de conversa" contribui para horizontalizar as relações entre os envolvidos na ação. A organização espacial dos participantes em círculos dá corporeidade à proposição de igualdade e liberdade dos participantes que se predispõem a falar ou silenciar ao sabor dos desejos e interesses. Compreende-se, também fundamentados na proposta educacional freireana (FREIRE, 1996, 1983), as rodas de conversa como "uma estratégia política libertadora, que favorece a emancipação humana, política e social de coletivos historicamente excluídos" (SILVEIRA; HILÁRIO; OLIVEIRA; MARTINS, 2012, p. 69), foi a concepção educacional adotada. Significa "uma postura ético-política em relação à produção do conhecimento e à transformação social, efetivando-se a partir das negociações entre sujeitos" e reflete a compreensão de construção do conhecimento como um "movimento contínuo de perceber - refletir - agir - modificar, em que os participantes podem se reconhecer como condutores de sua ação e da sua própria possibilidade de "ser mais" (SILVEIRA; HILÁRIO; OLIVEIRA; MARTINS, 2014, p. 69).

No Programa Papo Lírico, a leitura é interpretada como produção de sentido que depende da visão de mundo, do repertório de vida que envolve a cultura de classe do leitor, conforme estabelece Freire (1983), ao declarar a precedência da leitura da vida sobre a leitura

Revista Extensão \& Cidadania, v. 9, n. 16, p. 253-266, jul./dez. 2021. 
da palavra, a qual possibilita ao sujeito leitor a reescrita que envolve a autocompreensão e a reflexão sobre a realidade. Nesse sentido, a leitura pode ser vista como feita de camadas, cujo tecido envolve habilidades e traz dimensões psicológicas e linguísticas, históricas e sociais. Assim, permite tanto "compreender as práticas efetivas e concretas do ato de ler" quanto "situar-se, nessas práticas efetivas e concretas do ato de leitura, que é universalizado e apresentado, pelas investigações psicológicas e linguísticas, como a leitura" (BATISTA, 1991, p. 35).

Se a arte, ou seja, o objeto estético que é criação, conhecimento e expressão (BOSI, 2004), fosse uma colmeia, as paredes das celas, literatura e cinema, seriam dissolvidas em alguns pontos, dentre os quais o da linguagem e o da ficção. Esta que ocupa um grande espaço de intersecção entre a arte literária e a sétima arte foi mobilizada na atividade extensionista que ora se registra. A ficção pode ser compreendida como um processo de falar de algo enquanto quer se tornar a própria coisa de que fala. Seria, portanto, uma forma dotada de sentido que produz sentido para algo fora dela, àquilo com que se parece, àquilo a que poderia fazer referência. Essa existência outra o é enquanto ficção, fingimento, mentira, mas que avisa que é logro, jogo, que não é aquilo com o qual se parece e atua como se o fosse.

Wolfgang Iser (2002) analisa o texto ficcional de modo relacional, vendo nele um movimento entre o fictício, o real e o imaginário que o ativa. No texto literário os elementos de realidade são repetidos pelo que ele chama de "atos de fingir", os quais são transgressores de limites e dotados de intencionalidade, e, portanto, de sentido pela configuração do imaginário atuante. Esses atos são a seleção, a combinação e o desnudamento da ficcionalidade. Este último também tratado de "como se" remete à condição paradoxal da ficção que é como se fosse o mundo e, com isso, produz um efeito, ensina, ajuda a ordenar o pensamento, o mundo psíquico e sensibiliza estética e sentimentalmente. Tal proposição, retomada pelos teóricos da recepção e do efeito, remete à tradição. Na Arte poética (1, 3-16), Aristóteles (1994) concebe o fazer poético como mimesis, comumente traduzida como imitação, uma maneira do ser humano aprender, conhecer, inclusive a si mesmo, e com essa criação encontrar prazer.

Consubstanciadas e orientadas por essas reflexões teóricas, na época, foram realizadas reuniões com os participantes do Papo Lírico e os professores da Escola Anexa ao Conjunto Penal de Jequié, nas quais definiram-se os procedimentos de preparação das oficinas, tendo como suporte as competências gerais definidas na Base Nacional Comum Curricular (BNCC)

Revista Extensão \& Cidadania, v. 9, n. 16, p. 253-266, jul./dez. 2021. 
(BRASIL, 2018), documento de caráter normativo que define o conjunto orgânico e progressivo de aprendizagens essenciais que todos os alunos devem desenvolver ao longo das etapas e modalidades da Educação Básica. As competências que aspiram contribuir para a construção de uma sociedade mais ética, democrática, responsável e inclusiva, foram integradas ao projeto da escola como uma instância integradora e transversal.

A literatura e o cinema foram concebidos como arte para fruição, não como pretexto para outra coisa diferente de uma criação humana que humaniza, consoante proposto por Antonio Candido (CANDIDO, 1989). Flávio Aguiar (2012), em “O direito à literatura no século XXI: uma homenagem a Antonio Candido" explicita o que na aludida obra de Candido são os traços próprios da humanidade, os quais replica-se por embasar a ideia de humanidade aqui referida: "o exercício da reflexão"; "a aquisição do saber"; "a boa disposição para com o próximo"; "o afinamento das emoções"; "a capacidade de penetrar nos problemas da vida"; "o senso da beleza"; "a percepção da complexidade do mundo e dos seres"; "o cultivo do humor" e "a capacidade de fabulação". O articulista abre o seu texto com uma referência a um evento de 2012, que relembrava o "holocausto da inteligência", a "queima de livros considerados decadentes, subversivos, inadequados ao 'caráter alemão', que se realizaram em rituais macabros", ocorridos na mesma praça germânica, em 1933. Tal lembrança favorece a que se tenha ciência de outras e opostas características humanas que a fruição artística pode ajudar a combater como, por exemplo, "a negação da reflexão como estratégia de dominação"; "a satisfação com a própria ignorância e a dos outros, e seu estímulo programado"; "a capacidade de fugir ou negar os problemas da vida através de fantasias fanatizantes"; "a simplificação fanática do mundo e dos seres, em geral de forma maniqueísta e autocomplacente"; e "o cultivo do ressentimento e do amargor, e a confusão do humor com o sarcasmo destruidor do outro" (AGUIAR, 2012).

A seleção das obras ficcionais foi precedida pela definição dos temas transversais contemporâneos da BNCC (BRASIL, 2018) e o tamanho do texto. Os textos literários e cinematográficos deviam comportar temáticas similares, precisavam ser curtos para permitir a sua apresentação, leitura e discussão em, no máximo, 3 horas, carga horária disponibilizada nas aulas da Escola Anexa. Assim, as oficinas possibilitariam uma ligação com os componentes curriculares e as áreas de conhecimento, circunstanciando o ensino no imaginário dos educandos. O dia e hora possível para a ação foi a terça-feira das 8 horas e 30 minutos às 11

Revista Extensão \& Cidadania, v. 9, n. 16, p. 253-266, jul./dez. 2021. 
horas e 30 minutos, tempo que era destinado às aulas regulares e contava com a participação também do professor do componente curricular da área de Linguagens.

Em reuniões semanais presenciais, foram definidas e preparadas três oficinas que seguiram os mesmos passos definidos para a sua aplicação. Escolhidos os textos, estes eram submetidos a uma análise que mimetizava a prevista para realização da ação: apresentação sucinta do texto literário (autor, situação de produção), leitura, exposição de sensações e questões iniciais suscitadas, releituras para comentar a estrutura do texto, relacioná-lo às condições de produção e debates as questões propostas. Depois a exibição do filme, seguida dos mesmos passos e uma ampliação da discussão.

O tema prioritário escolhido para fundamentar a escolha dos textos inseriu-se no que a BNCC (BRASIL, 2018) denomina macroárea temática, no caso a "Cidadania e civismo" Contudo, uma das forças de liberdade da ficção capacita a aventar outros e novos temas que também atravessam os textos. A condição potente, apontada por Roland Barthes na sua famosa Aula, referia-se à literatura, mas a atribuímos aqui à ficção que realiza um deslocamento em relação ao seu material. Os poderes de liberdade destacados pelo semiólogo francês foram "Mathesis, Mimesis, Semiosis". A ficção, ao recriar e significar um mundo como se fosse real (Mimesis), quer ser o real, tem a força do real (Semiosis), e por força da Mathesis, ela é enciclopédica, "assume muitos saberes", fá-los girar, "não fixa, não fetichiza nenhum deles; ela lhes dá um lugar indireto, e esse indireto, é preciso" (BARTHES, 1978). Por conseguinte, temas de outras macroáreas também foram acolhidos ou perpassam os textos. Esse cenário possibilitaria a retomada dos textos pelos professores da Escola Anexa nas suas ações regulares.

Para a primeira oficina, foram escolhidos o conto A menina que roía as unhas, de Helena Parente Cunha (1998) e o curta de animação Vida Maria (2006), de Márcio Ramos, fundamentados no tema da desigualdade, nos quais se insere a questão da mulher na sociedade, o trabalho infantil e o "ciclo vicioso" de espectro mais amplo, estes se relacionam às macroárias "Saúde" e "Diversidade cultural" (BRASIL, 2018). O relato de Euclides Neto (2014) É proibido menino calçado frequentar escola e o curta que lhe dramatiza É proibido menino calçado entrar na escola (2013) cujo roteiro, direção e montagem são de Edson Bastos e Henrique Filho, a canção Senhor cidadão (1972) de Tom Zé e o poema Pan Cinema permanente (1996) de Waly Salomão foram as obras da segunda oficina, selecionados pelas suas abordagens acerca da cidadania e a desigualdade social. Para a terceira oficina, a escolha

Revista Extensão \& Cidadania, v. 9, n. 16, p. 253-266, jul./dez. 2021. 
recaiu sobre o curta Birdon (2010) de Adelan Cynillo, o poema Gaiola (2005) de Mayrant Gallo e Existência, poema de Natanael, autor de um dos textos de Sentimentos internos (2018), obra resultante do projeto Café com Poesia, criado e desenvolvido pelos professores da Escola Anexa, Domingos Calixto, Janei Reis, Josivanda Almeida e Elenita Aragão. Estes textos, unificados pelo tema da liberdade, possibilitam a abordagem de temáticas da macroárea de "Saúde" e "Ciência e Tecnologia" (BRASIL, 2018).

\section{Discussão e resultados}

Apenas as duas primeiras oficinas foram desenvolvidas na Escola Anexa, elas cumpriram-se no período de 19 de setembro a 30 de outubro de 2018. A primeira aconteceu em todos os cinco módulos, a segunda, apenas nos 4 módulos masculinos, pois, no dia definido para efetivar-se no módulo feminino, a professora do horário estava concluindo outra atividade e não disponibilizou a classe. Todas as oficinas foram orientadas por três membros do Papo Lírico que contavam também com o auxílio dos professores do horário.

A primeira oficina foi antecedida pela apresentação da equipe e foi recebida com curiosidade e certo acanhamento, por ser, segundo depoimentos, "uma atividade diferente" e, provavelmente, por envolver pessoas de fora, de outra instituição. Mas, à medida que eram instados a falar, a maioria dos alunos aventaram considerações, reconheceram-se nas histórias, contavam as próprias, emocionaram-se, riam, se divertiam, e entristeceram-se, apresentavam questionamentos que, aos poucos, geravam discussões. Como era esperado, abordaram questões e enfatizaram aspectos algumas vezes diferentes daqueles ensaiados durante a preparação da ação. Alguns alunos participaram mais que outros, houve os que tentaram monopolizar a discussão, os que foram desconsiderados ou ouvidos com respeito pelos colegas. E também houve alunos que, mesmo convocados, mantiveram-se em silêncio participativo ou distante.

Visualmente, as ficções foram vivenciadas plenamente pela maioria dos alunos. Contudo, como a ficção é um lugar que é também outro, é possível que mesmo aqueles que não se manifestaram tenham usufruído a experiência que era o propósito do Papo Lírico: ler para ser; ser, lendo, falando, rememorando, sonhando... Ou seja, humanizando-se, mesmo que no lugar de violência que são os presídios e por poucos minutos. Isso pode parecer irrelevante, mas

Revista Extensão \& Cidadania, v. 9, n. 16, p. 253-266, jul./dez. 2021. 
não é. Insistir em ser humano com o outro, seja lá quem ele for, se na sociedade movida pelo e para o lucro já é perigoso ainda o é mais no espaço de brutalização sobre o qual discutiu Carrascosa (2015).

As oficinas de leitura de literatura e cinema viabilizaram a instauração, nas classes situadas nos módulos do Conjunto Penal de Jequié, a experiência de um "entre lugar". A vivência ficcional abre caminho para paragens evasivas e para olhar-se e ao entorno por outro(s) prisma(s), possuído, "rico/ maduro de viagens/ e multilustrado!", como elaborado por Ruy Espinheira Filho no poema Tempo perdido, cuja estrofe final faz ver uma ótica subversiva característica do deslocamento ocasionado pela ficção: "No tempo perdido/ recupero, enfim,/ tudo o que perdi/ no meu tempo ganho" (ESPINHEIRA, 1998, p. 15-16). O fazer artístico, pode-se ler, é tempo perdido do ponto de vista do trabalho na sociedade capitalista, mas leva ao encontro do sonho, da fantasia, do desejo, da reflexão, da criação e de um fazer que humaniza e possibilita a utopia e ser outro no espaço do instante da leitura.

Houve um pequeno estranhamento inicial, mas aos poucos, timidamente, os participantes aventuravam considerações, lembranças, reflexões sobre a vida e a opinião sobre os assuntos abordados que geravam muitas discussões. A percepção da estrutura das materialidades analisadas foi praticamente inexistente, embora tenha sido apontada pelos professores presentes. Os leitores produziram leituras dos textos que remetiam criticamente à realidade brasileira e, ao mesmo tempo, a eles mesmos, suas histórias, sonhos e problemas.

\section{Considerações finais}

As oficinas foram também desenvolvidas em outros lugares da cidade de Jequié. A primeira oficina foi levada na Praça da Amizade, ambiente cuidado por moradores do Conjunto Urbis I, localidade do bairro do Jequiezinho; as duas primeiras foram vivenciadas em espaço terapêutico de um Centro de Atenção Psicossocial Álcool e Outras Drogas (CAPS-AD) e na VIII Semana de Letras da UESB, evento universitário. As particularidades do espaço e do público não modificaram a metodologia e nem a boa recepção e o entusiasmo final dos participantes. A maior diferenciação compreensivelmente ocorreu na abordagem da estrutura das materialidades analisadas, tendo em vista que o grupo acadêmico era formado por estudantes do curso de Letras.

Revista Extensão \& Cidadania, v. 9, n. 16, p. 253-266, jul./dez. 2021. 
A pandemia da Covid-19 exacerbou o individualismo, o distanciamento e a desigualdade social, além de acentuar o adoecimento físico e mental. Essas profundas transformações sociais afetaram diretamente diversos setores da sociedade, dentre os quais o sistema educacional. $\mathrm{Na}$ verdade, a educação sempre percorreu caminhos longos e fragilizados, luta-se, há muito, pela democratização de um ensino mais humano, que defenda um projeto justo e inclusivo, avesso à centralidade polarizada e hegemônica, evidenciada fortemente, durante o período pandêmico.

Nesse cenário que separou ainda mais as pessoas, as oficinas e rodas de conversa com materialidades artísticas podem ser alternativas viáveis e versáteis de promover novos modos de relação em ambientes diferentes, socioeducativos e prisionais ou não para forjar brechas que se oponham à crescente onda segregacionista que tem separado ainda mais classes e grupos sociais brasileiros.

\section{Referências}

AGUIAR, Flávio. O direito à literatura no século XXI: uma homenagem a Antonio Candido. In: BLOG DA BOITEMPO. São Paulo, 31 maio 2012. Disponível em: https://blogdaboitempo.com. br/2012/05/31/o-direito-a-literatura-no-seculo-xxi-umahomenagem-a-antonio-candido-por-flavio-aguiar/. Acesso em: 19 jul. 2021.

ANASTASIOU, Léa das Graças Camargos; ALVES, Leonir Pessate (org.). Processos de ensinagem na universidade. Pressupostos para as estratégias de trabalho em aula. 3. ed. Joinville: Univille, 2004.

ARISTÓTELES. Poética. Tradução, prefácio, introdução e comentários de Eudoro de Sousa. S/l: Imprensa Nacional, Casa da Moeda, 1994.

BAHIA. Provimento da Corregedoria Geral de Justiça nº 03/2016. 2016. Disponível em: http://www7.tj.ba.gov.br/secao/arquivo/23/17349/PROVIMENTO\%20CGJ\%2003\%202016\% 20CONJUNTO\%20PENAL\%20CONQUISTA\%20pdf.pdf. Acesso em: 12 set. 2021.

BARTHES, Roland. Aula (aula inaugural da cadeira de semiologia literária do Colégio de França, pronunciada no dia 7 de janeiro de 1977). Trad. Leyla Perrone Moisés. São Paulo: Cultrix, 1978.

BATISTA, Antônio Augusto Gomes. Sobre a leitura: notas para uma concepção de leitura de interesse pedagógico. Em aberto, Brasília, ano 10, n. 52, out./dez. 1991.

BIRDON. Direção, roteiro e edição: Adelan Cynillo. Animação. 2010. Duração: 4min06seg.

Revista Extensão \& Cidadania, v. 9, n. 16, p. 253-266, jul./dez. 2021. 
BOSI, Alfredo. Reflexões sobre a arte. São Paulo: Ática, 2004.

BRASIL. Lei de Execução Penal no 7.210, de 11 de julho de 1984. Institui a Lei de Execução Penal. Brasil, DF, 1984. Disponível em:

www.planalto.gov.br/ccivil_03/LEIS/L7210.htm. Acesso em: 2 fev. 2020.

BRASIL. Lei de Diretrizes e Bases da Educação Nacional $n^{\circ}$. 9.394, de 20 de dezembro de 1996. Estabelece as diretrizes e bases da educação nacional. Brasília, DF, 1996. Disponível em: http://www.planalto.gov.br/ccivil_03/Leis/L9394.htm. Acesso em: 12 ago. 2021. BRASIL. Ministério da Educação. Temas contemporâneos transversais na BNCC. Contexto histórico e pressupostos pedagógicos. Brasília, DF, 2018. Disponível em: http:// basenacionalcomum.mec.gov.br/images/implementacao/contextualizacao_temas_contempora neos.pdf. Acesso em: 16 jul. 2021.

CALIXTO, Domingos; REIS, Janei; ALMEIDA, Josivanda; ARAGÃO, Elenita (org.). Sentimentos internos. Coletânea. Jequié: Nocego, 2018.

CANDIDO, Antonio. Direitos humanos e literatura. São Paulo: Brasiliense, 1986. p. 107126.

CARRASCOSA, Denise. Técnicas e políticas de si nas margens, seus monstros e heróis, seus corpos e declarações de amor. Literatura e prisão no Brasil pós-Carandiru. Curitiba: Appris, 2015.

CUNHA, Helena Parente. Vento, ventania, vendaval. Rio de Janeiro: Tempo Brasileiro; Salvador: Fundação João F. Cunha, 1998.

É PROIBIDO menino calçado entrar na escola. Direção, roteiro e montagem: Edson Bastos e Henrique Filho. Produção: Voo Audiovisual. Ipiaú-BA-BR. 2013. Duração: 5 min., son., color.

ESPINHEIRA FILHO, Ruy. Poesia reunida e inéditos. Rio de Janeiro: Record, 1998.

FERNANDES, Daniel Fonseca. O ensino entre pedras e grades: percepções sobre a educação escolar na Penitenciária Lemos Brito. 2018. 146 f. Dissertação (Mestrado em Direito) - Faculdade de Direito, Universidade Federal da Bahia, Salvador, 2018.

FOUCAULT, Michael. Microfísica do Poder. Trad. Roberto Machado. Rio de Janeiro: Edições Graal, 1979.

FREIRE, Paulo. A importância do ato de ler e três artigos que se complementam. São Paulo: Cortez; Autores Associados, 1983.

FREIRE, Paulo. Pedagogia da autonomia: saberes necessários à pratica educativa. São Paulo: Paz e Terra, 1996.

GALLO, Mayrant. Recordações de andar exausto. Salvador: Aboio Livre Edições, 2005.

Revista Extensão \& Cidadania, v. 9, n. 16, p. 253-266, jul./dez. 2021.

ISSN 2319-0566 DOI: 10.22481/recuesb.v9i16.9632 
ISER, Wolfgang. Os atos de fingir ou o que é fictício no texto ficcional. In: LIMA, Luiz Costa (org.). Teoria da literatura em suas fontes. 3. ed. Rio de Janeiro: Civilização Brasileira, 2002. v. 2. p. 955-987.

MAIA, Clarissa Nunes. Histórias das prisões no Brasil. Rio de Janeiro: Rocco, 2009.

MARQUES, Rosa Maria; LEITE, Marcel Guedes; BERWING, Solange Emilene; DEPIERI, Marcelo Álvares de Lima. Pandemia, crises e capitalismo. São Paulo: Expressão Popular, 2021.

NETO, Euclides. 64: um prefeito, a revolução e os jumentos. 2. ed. Salvador: EDUFBA; São Paulo: Littera Criações, 2014.

SALOMÃO, Waly. Algaravias: Câmara de ecos. Rio de Janeiro: Ed. 34, 1996.

SILVEIRA, Ana Paula Trevisan da; HILÁRIO, Valter Colombo; OLIVEIRA, Patrícia Bertoli de; MARTINS, Simone Regina. Oficina pedagógica na EJA: a tecnologia e a transformação no espaço. Revista Tessituras Geográficas - FACCOS/CNEC, Osório, v. 1, n. 1, dez. 2012. Disponível em:

http://facos.edu.br/publicacoes/revistas/tessituras_geograficas/dezembro_2012/pdf/oficina_pe dagogica_no_eja_-_a_tecnologia_e_a_transformacao_no_espaco.pdf.Acesso em: 10 jul. 2021.

VIDA Maria. Direção, roteiro e edição: Márcio Ramos. Animação. Colorido. Produção Joelma Ramos e Márcio Ramos. Coprodução: Trio filmes, VIACGPaís: Ceará-Brasil. Ano: 2006. 9 min, son., color., $35 \mathrm{~mm}$.

VIEIRA, Elaine; VOLQUIND, Lea. Oficinas de ensino: O quê? Por quê? Como? 4. ed. Porto Alegre: Edipucrs, 2002.

ZÉ, Tom. Senhor cidadão. In: Se o caso é chorar. São Paulo: Continental, 1972. Disco sonoro, Lado A, Faixa 3.

Recebido: 13.10.2021

Aceito: 23.11 .2021

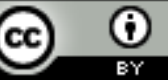

This work is licensed under a Creative Commons Attribution 4.0 International License.

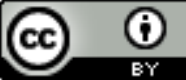

Este trabalho está licenciado com uma Licença Creative Commons - Atribuicãa 4.0

Internacional.

Revista Extensão \& Cidadania, v. 9, n. 16, p. 253-266, jul./dez. 2021.

ISSN 2319-0566 DOI: 10.22481/recuesb.v9i16.9632 